\title{
Correlation of Inferior Vena Cava diameter and IVC Collapsibility Index with Central Venous Pressure (CVP) in critically ill surgical patients
}

\author{
Deepak Raj Singh ${ }^{1}$, Anurag Singh Thapa ${ }^{2}$, Yugal Limbu ${ }^{3}$, Sampanna Pandey ${ }^{3}$, Swechha Shrestha ${ }^{4}$
}

\section{Abstract}

\section{Introduction}

Central Venous Pressure is a valuable parameter in the management of critically ill surgical patients in the ICU. Non-invasive methods to extrapolate the volume status of the patient can aid clinicians in expediting proper treatment. The objective of this study is to find a correlation between Inferior Vena cava (IVC) diameter and collapsibility index (CI) with Central venous pressure (CVP) in critically ill surgical patients.

\section{Methods}

This cross-sectional study included 60 critically ill patients from September 2020 - 31st February 2021. We recorded the patient's age, sex, heart rate, blood pressure, CVP, volume status, IVC minimum, and maximum diameter. After taking consent and explaining the procedure to the patient, the maximum IVC anteroposterior diameter was noted at the end of inspiration and end of expiration in centimeters. IVC collapsibility index was calculated using the formula ([IVCdmaxIVCdmin]/IVCdmax*100\%). Following this, the CVP of the patient was measured.

\section{Results}

Among the patients evaluated, 32 were females. The mean age of the participants was $44.90 \pm 15.76$ years. The mean central venous pressure maintained was $11.10 \pm 2.11 \mathrm{~cm} \mathrm{H} 2 \mathrm{O}$ with an inferior vena cava collapsibility index of $29.69 \pm 8.75$. There was a negative correlation between CVP and IVC collapsibility index (\%), which was statistically significant $(\mathrm{r}=-0.701, \mathrm{n}=60, \mathrm{p}<0.01)$. A strong positive correlation between CVP and maximum IVC diameter $(r=0.712, n=60, p<0.01)$ and minimum IVC diameter $(r=0.796, n=60, p<0.01)$ was found.

\section{Conclusion}

Inferior Vena Cava diameter and IVC Collapsibility Index can be used as a reliable substitute to central venous pressure to determine the patient's volume status.

Keywords: Central venous Pressure; IVC collapsibility index; IVC diameter.
Author affiliations:

'Department of Surgery, KIST Medical College Teaching Hospital, Lalitpur, Nepal. ${ }^{2}$ Department of Plastic Surgery, NAMS, Bir Hospital, Kathmandu, Nepal.

${ }^{3}$ Department of Surgery, Kathmandu Medical College Teaching Hospital, Kathmandu, Nepal.

${ }^{4}$ Department of Anaesthesia, Kathmandu Medical College Teaching Hospital, Kathmandu, Nepal.

Correspondence:

Dr. Deepak Raj Singh, Associate Professor, Department of Surgery, KIST Medical College Teaching Hospital, Lalitpur, Nepal.

Email: drsinghnp@gmail.com

ORCID: https://orcid.org/ 0000-0001-8174-9619

Disclosures:

Ethical Clearance: IRB of KMCTH

Conflict of interest: None

Financial aid: None

Copyright information:

Authors retain copyright and grant the journal right of first publication with the work simultaneously licensed under Creative Commons Attribution License under CC-BY 4.0 that allows others to share the work with an acknowledgement of the works's authorship and initial publication of this journal.

\section{How to cite this article:}

Singh DR, Thapa AS, Limbu Y, Pandey S, Shrestha S. Correlation of inferior vena cava diameter and IVC collapsibility index with central venous pressure (CVP) in critically ill surgical patients. J Soc Surg Nep. 2021 Jul; 24(1):19-22.

DOI:

https://doi.org/10.3126/jssn.v24i1.41005 


\section{Introduction}

An accurate assessment of the extracellular volume status is an essential factor in properly diagnosing and managing critically ill patients. ${ }^{1,2}$ Although monitoring central venous pressure through the insertion of a central venous catheter is regarded as the gold standard, it is invasive and timeconsuming. ${ }^{3}$ Moreover, several complications related to central venous catheter insertion include injury to local structures, phlebitis at the insertion site, air embolism, hematoma, arrhythmia, and catheter malposition. ${ }^{4}$ A noninvasive and cost-effective method like sonoscopy in ICU can guide the clinician in fluid therapy by determining IVC diameter. Size of IVC changes with respiration and total body fluid. ${ }^{5}$ Since the IVC diameter exhibits a variation with the respiratory cycle, several authors have measured both the inspiratory and the expiratory diameters of the IVC and used them to calculate the collapsibility index. Few studies have reported that a $50 \%$ collapse of the IVC diameter during a respiratory cycle is associated with a low CVP. ${ }^{6,7}$

\section{Methods}

This cross-sectional observational study was carried out in the intensive care unit (ICU) of Kathmandu Medical College Teaching Hospital, Sinamangal, Nepal. A total of 60 participants were enrolled from 1st September 2020 to 31 st February 2021. Spontaneously breathing patients $\geq 18$ years old who were admitted to the ICU and who had a central venous catheter inserted (subclavian or internal jugular vein) were included in the study. The exclusion criteria included patients younger than 18 years old, mechanically ventilated patients, patients under CPAP or BiPAP (non-invasive ventilation), patients who were morbidly obese, rendering them unsuitable for bedside sonoscopy to measure IVC, and patients who refused to participate. The sample size was calculated to be 55 using the Cochrane sample size equation, taking the confidence interval of $95 \%$, margin of error at $8 \%$, and the prevalence of septic shock in critically ill patients at $10 \% 8$.

Informed consent was taken from all the participants, and ethical approval was obtained from the local ethical committee (Ref:1208202001). The study was done for a total duration of six months. While obtaining the IVC diameter through bedside sonoscopy, the investigators were blinded to CVP measurement.

The bedside sonoscopy of all the patients was performed using a Mindray portable ultrasonography machine model Z6 (Mindray, NJ, USA) ${ }^{\circ}$ by surgical residents trained in basic bedside sonoscopy. Initially, the patients were kept in the supine position, and the ultrasound gel was applied to the sub-xiphoid region. The IVC was visualized using a curvilinear probe in the subxiphoid location in the longitudinal axis $2 \mathrm{cms}$ distal to IVC-hepatic vein junction. IVC diameter at the end of inspiration and end of expiration were measured. The maximum IVC diameter $\left(\mathrm{IVCd}_{\max }\right.$ was measured as the maximum anterior- posterior dimension at end-expiration, and the minimum IVC diameter was measured at end-inspiration $\left(\mathrm{IVCd}_{\min }\right.$. The IVC collapsibility index was the difference between the maximum and minimum IVC diameters divided by the maximum IVC diameter, expressed as a percentage $\left(\left[\mathrm{IVCd}_{\max }-\mathrm{IVCd}_{\min }\right] / \mathrm{IVCd}_{\max } \times 100 \%\right)$. The CVP was measured while the patient was in supine position. The vertical distance between the angle of Louis (manubriumsternal joint) and the highest level of the meniscus in the CVP catheter at the end of expiration was measured using a ruler. In the end, we added $5 \mathrm{~cm}$ to the measurement since the right atrium is $5 \mathrm{~cm}$ below the sternal angle. The patients having CVP between $8-12 \mathrm{cmH}_{2} \mathrm{O}$ were considered euvolemic, patients having CVP> $>12 \mathrm{cmH}_{2} \mathrm{O}$ were considered hypervolemic, and patients having CVP $<8 \mathrm{~cm} \mathrm{H}_{2} 0$ were considered hypovolemic. ${ }^{4}$

\section{Statistical analysis:}

The data were entered and analyzed in SPSS version 21 (IBM, NY, USA). Descriptive statistics were calculated for all qualitative variables. One-way analysis of variance (ANOVA) was used to compare the three groups of patients with different intravascular volume statuses, and Tukey's method was used for posthoc multiple comparisons. Pearson correlation coefficient was used to assess the significance between CVP and IVC collapsibility index (\%) and the maximum and minimum IVC diameter. A p-value less than 0.05 was considered to be significant.

\section{Results}

A total of $28(46.66 \%)$ males and $32(53.33 \%)$ females were included in the study with a mean age of $44.90 \pm 15.76$ years. A total of $24(40 \%)$ central venous catheter (CVC) insertion was performed using the subclavian approach, and the rest were performed using the internal jugular approach.

Table 1. Demography of the patients $(n=60)$

\begin{tabular}{|l|c|}
\hline Characterstics & \multicolumn{1}{c|}{ Values } \\
\hline $\begin{array}{l}\text { Age of patient } \\
\text { (Mean } \pm \text { Standard Deviation) }\end{array}$ & $44.90 \pm 15.76$ \\
\hline Male participants & $28(46.44 \%)$ \\
\hline Subclavian insertion of CVC & $24(40 \%)$ \\
\hline Internal jugular insertion of CVC & $36(60 \%)$ \\
\hline Euvolemic group & $44(73.33 \%)$ \\
\hline Hypervolemic group & $16(26.66 \%)$ \\
\hline
\end{tabular}

The mean heart rate was $90.50 \pm 12.42$ per minute. The mean central venous pressure maintained was $11.10 \pm 2.113$ $\mathrm{cmH}_{2} \mathrm{O}$ with the inferior vena cava collapsibility index of $29.69 \pm 8.75$. The central venous pressure (CVP) was found to be less than eight $\mathrm{cmH}_{2} \mathrm{O}$ in none of the patients, while 44 (73.33\%) had CVP between 8-12 $\mathrm{cmH}_{2} \mathrm{O}$ and 16 (26.66\%) patients had CVP greater than $12 \mathrm{cmH}_{2} 0$. The mean inferior vena cava (IVC) minimum diameter was $1.44 \pm 0.36 \mathrm{~cm}$, and the maximum diameter was $2.025 \pm 0.31 \mathrm{~cm}$. 
Correlation of Inferior Vena Cava diameter and IVC Collapsibility Index with Central Venous Pressure (CVP) in critically ill surgical patients

Table 2. Parameter assessment with volume status

\begin{tabular}{|l|l|l|l|}
\hline Parameters & $\begin{array}{l}\text { Euvolemia } \\
(\mathbf{n = 4 4 )}\end{array}$ & $\begin{array}{l}\text { Hypervolemia } \\
(\mathbf{n = 1 6})\end{array}$ & $\begin{array}{l}\text { ANOVA } \\
\text { (p-value) }\end{array}$ \\
\hline $\begin{array}{l}\text { Heart rate (per } \\
\text { minute) }\end{array}$ & $90.50 \pm 10.64$ & $80.87 \pm 16.04$ & 0.012 \\
\hline $\begin{array}{l}\text { IVC collapsibili- } \\
\text { ty index }\end{array}$ & $33.15 \pm 6.95$ & $20.17 \pm 5.75$ & 0.087 \\
\hline $\begin{array}{l}\text { IVC maximum } \\
\text { diameter }\end{array}$ & $1.906 \pm 0.266$ & $2.35 \pm 0.159$ & 0.001 \\
\hline $\begin{array}{l}\text { IVC minimum } \\
\text { diameter }\end{array}$ & $1.279 \pm 0.25$ & $1.881 \pm 0.228$ & 0.001 \\
\hline
\end{tabular}

[Hypovolemia $\mathrm{CVP}<8 \quad \mathrm{cmH}_{2} \mathrm{O}$, Euvolemia $\mathrm{CVP} \quad 8-12 \quad \mathrm{cmH}_{2} \mathrm{O}$, Hypervolemia $\left.\mathrm{CVP}>12 \mathrm{cmH}_{2} \mathrm{O}\right]$

A Pearson correlation was run to determine the relationship between the central venous pressure values and the inferior vena cava collapsibility index (\%) and the maximum and minimum inferior vena cava diameter. A negative linear correlation was observed between the central venous pressure $\left(11.10 \pm 2.11 \mathrm{cmH}_{2} \mathrm{O}\right)$ and the inferior vena cava collapsibility index $(\%)(29.69 \pm 8.75)$, which was statistically significant $(\mathrm{r}=-0.701, \mathrm{p}<0.01)$. A strong positive correlation was revealed between the central venous pressure $\left(11.10 \pm 2.11 \mathrm{cmH}_{2} \mathrm{O}\right)$ and the maximum inferior vena cava diameter $(2.025 \pm 0.31 \mathrm{~cm})(\mathrm{r}=0.712$, $\mathrm{p}<0.01)$ and the minimum IVC diameter $(1.44 \pm 0.36 \mathrm{~cm})$ $(\mathrm{r}=0.796, \mathrm{p}<0.01)$. The correlation is represented in Figure 1.

\section{Discussion}

In the present study, a prospective cross-sectional study of 60 patients in the intensive care unit, the largest proportion of patients $(73.33 \%)$ were in a euvolemic state, and the rest $(26.66 \%)$ were in a hypervolemic state. The study's outcome revealed a positive correlation between Central Venous Pressure (CVP) and IVC diameter. Moreover, the study also compared CVP with IVC-CI, which was found to be inversely related. These results corroborate with findings of other studies like the one done by Stawicki SP et al. ${ }^{9}$ They have illustrated that IVC-CI strongly correlates with CVP in the setting of low $(\leq 20 \%)$ and high $(\geq 60 \%)$ collapsibility ranges. However, Prekker et $\mathrm{al}^{10}$ showed that a significant correlation between central venous pressure (CVP) and IVC collapsibility index (IVC-CI) was not always seen.

During inspiration, the intrapleural pressure becomes negative, which causes an increase in the venous return to the right side of the heart and a decrease in intraluminal pressure of the IVC. The lumen of the inferior vena cava begins narrowing at the beginning of the inspiration and reaches the narrowest diameter at the end of inspiration. The IVC expands during expiration, Valsalva maneuver, or positive pressure ventilation due to increased intrathoracic pressure. Therefore, inferior vena cava diameter measurement by ultrasonography is a valuable method for predicting central venous pressure. ${ }^{11-12}$
Assessment of intravascular fluid status is essential in the proper diagnosis and management of critically ill patients. There are various methods to monitor the intravascular fluid status in the patient. Among them, sonoscopic measurement of IVC diameter or collapsibility index (CI) and CVP measurement using the central venous catheter is the most commonly used methods. ${ }^{11} \mathrm{CVP}$ measurement requires invasive central venous catheter placement, which is timeconsuming and often trying in urgent situation. ${ }^{12}$ However, bedside sonoscopic evaluation of the IVC could provide an immediate measure of volume status at the emergency room or in transit of the patient to an intensive care unit. ${ }^{13}$ It is advantageous as it is a safe, non-invasive, and easily performed procedure compared to inserting a central venous catheter. In the past, the IVC diameter evaluation was used by nephrologists in hemodialysis patients to assess intravascular volume status. Subsequently, this technique has been performed by critical care specialists for determining body fluid volume status in critically ill patients. ${ }^{13-14}$

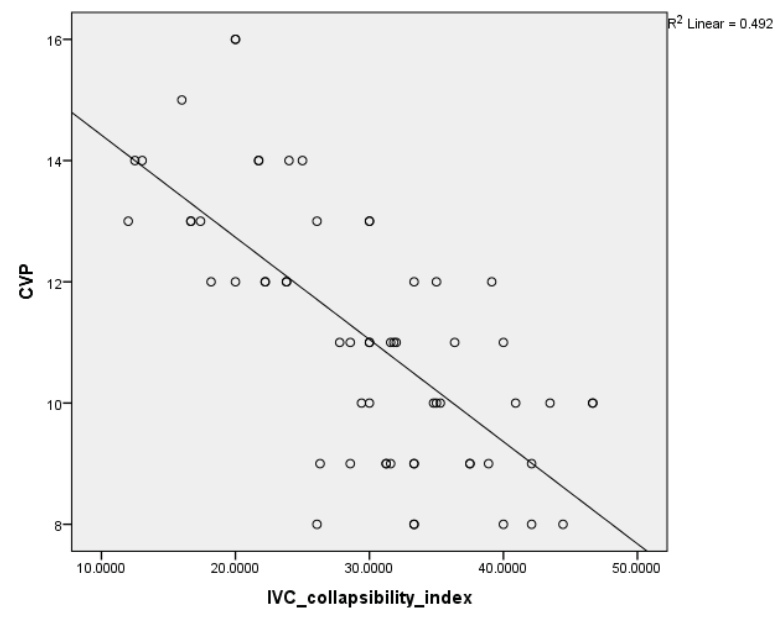

Figure 1. Pearson correlation between CVP and IVC collapsibility index

Our study has a few limitations, such as being performed in a single institute with small sample size. Moreover, the absence of hypovolemic patients in this study may affect the final data. Multiple observers were involved in measuring the IVC diameter using the ultrasound machine, which may have inter-observer variability. Further studies with a large sample size have to be done to externally validate this corelation.

\section{Conclusion}

The study shows a correlation between IVC diameter measured by sonoscopy and the conventional CVP measurement of the patient. Using simple bedside sonoscopy, we can assess the volume status of the patients while avoiding the potential complications of CVP insertion in critically ill patients in ICU. Therefore, we advocate teaching critical care doctors and residents to use sonoscopy to assess the patients' volume status. 


\section{References}

1. Rivers E, Nguyen B, Havstad S, Ressler J, Muzzin A, Knoblich B, et al. Early Goal-Directed Therapy in the Treatment of Severe Sepsis and Septic Shock. N Engl J Med. 2001;345(19):1368-77.

2. Boyd JH, Forbes J, Nakada TA, Walley KR, Russell JA. Fluid resuscitation in septic shock: A positive fluid balance and elevated central venous pressure are associated with increased mortality. Crit Care Med. 2011;39(2):259-65.

3. Roger C, Muller L, Riou B, Molinari N, Louart $\mathrm{B}$, Kerbrat $\mathrm{H}$, et al. Comparison of different techniques of central venous pressure measurement in mechanically ventilated critically ill patients. $\mathrm{Br} \mathrm{J}$ Anaesth. 2017;118(2):223-31.

4. Ilyas A, Ishtiaq W, Assad S, Ghazanfar H, Mansoor S, Haris M, et al. Correlation of IVC Diameter and Collapsibility Index With Central Venous Pressure in the Assessment of Intravascular Volume in Critically Ill Patients. Cureus. 2017;9(2).

5. Natori H, Tamaki S, Kira S. Ultrasonographic evaluation of ventilatory effect on inferior vena caval configuration. Am Rev Respir Dis. 1979;120(2):4217.

6. Nagdev AD, Merchant RC, Tirado-Gonzalez A, Sisson CA, Murphy MC. Emergency Department Bedside Ultrasonographic Measurement of the Caval Index for Noninvasive Determination of Low Central Venous Pressure. Ann Emerg Med. 2010;55(3):290-5.

7. Fields JM, Lee PA, Jenq KY, Mark DG, Panebianco NL, Dean AJ. The interrater reliability of inferior vena cava ultrasound by bedside clinician sonographers in emergency department patients. Acad Emerg Med. 2011;18(1):98-101.
8. Vincent JL, Jones G, David S, Olariu E, Cadwell KK. Frequency and mortality of septic shock in Europe and North America: A systematic review and meta-analysis. Crit Care 2019;23(1):34-45.

9. Stawicki SP, Braslow BM, Panebianco NL, Kirkpatrick JN, Gracias VH, Hayden GE, et al. Intensivist Use of Hand-Carried Ultrasonography to Measure IVC Collapsibility in Estimating Intravascular Volume Status: Correlations with CVP. J Am Coll Surg. 2009;209(1):55-61.

10. Prekker ME, Scott NL, Hart D, Sprenkle MD, Leatherman JW. Point-of-care ultrasound to estimate central venous pressure: a comparison of three techniques. Crit Care Med. 2013 Mar;41(3):833-41.

11. Scales K. Central venous pressure monitoring in clinical practice. Nurs Stand. 2010;24(29):4955; quiz 56.

12. Ruesch S, Walder B, Tramèr MR. Complications of central venous catheters: Internal jugular versus subclavian access - A systematic review. Crit Care Med. 2002;30(2):454-60.

13. Maecken T, Grau T. Ultrasound imaging in vascular access. Crit Care Med. 2007 May;35(5 Suppl): S178-85.

14. Krause I, Birk E, Davidovits M, Cleper R, Blieden $\mathrm{L}$, Pinhas $\mathrm{L}$, et al. Inferior vena cava diameter: A useful method for estimation of fluid status in children on haemodialysis. Nephrol Dial Transplant. 2001;16(6):1203-6. 